Studies on the biodistribution of dextrin nanoparticles

This article has been downloaded from IOPscience. Please scroll down to see the full text article.

2010 Nanotechnology 21295103

(http://iopscience.iop.org/0957-4484/21/29/295103)

View the table of contents for this issue, or go to the journal homepage for more

Download details:

IP Address: 193.137.90.1

The article was downloaded on 07/09/2012 at 10:33

Please note that terms and conditions apply. 


\title{
Studies on the biodistribution of dextrin nanoparticles
}

\author{
C Gonçalves ${ }^{1}$, M F M Ferreira ${ }^{2}$, A C Santos ${ }^{3}$, M I M Prata ${ }^{3}$, \\ C F G C Geraldes ${ }^{4}$, J A Martins ${ }^{2}$ and F M Gama ${ }^{1}$ \\ ${ }^{1}$ IBB-Institute for Biotechnology and Bioengineering, Centre for Biological Engineering, \\ Minho University, Campus de Gualtar, 4710-057 Braga, Portugal \\ 2 Departamento de Química, Universidade do Minho, Campus de Gualtar, 4710-057 Braga, \\ Portugal \\ ${ }^{3}$ IBILI, Faculty of Medicine of the University of Coimbra, Coimbra, Portugal \\ ${ }^{4}$ Departamento de Ciências da Vida, Faculdade de Ciência e Tecnologia e Centro de \\ Neurociências e Biologia Celular, Universidade de Coimbra, Portugal \\ E-mail: fmgama@deb.uminho.pt
}

Received 25 March 2010, in final form 26 March 2010

Published 5 July 2010

Online at stacks.iop.org/Nano/21/295103

\begin{abstract}
The characterization of biodistribution is a central requirement in the development of biomedical applications based on the use of nanoparticles, in particular for controlled drug delivery. The blood circulation time, organ biodistribution and rate of excretion must be well characterized in the process of product development. In this work, the biodistribution of recently developed self-assembled dextrin nanoparticles is addressed. Functionalization of the dextrin nanoparticles with a DOTA-monoamide-type metal chelator, via click chemistry, is described. The metal chelator functionalized nanoparticles were labelled with a $\gamma$-emitting ${ }^{153} \mathrm{Sm}^{3+}$ radioisotope and the blood clearance rate and organ biodistribution of the nanoparticles were obtained. The effect of PEG surface coating on the blood clearance rate and organ biodistribution of the nanoparticles was also studied.
\end{abstract}

S Online supplementary data available from stacks.iop.org/Nano/21/295103/mmedia

\section{Introduction}

Nanomedicine has emerged in recent years as an exciting area for chemists, materials scientists, engineers and medical doctors, converging in the development of new tools for diagnostics and therapeutics [1-3]. A rather large number of nanostructures have been developed over the past few decades. Well-defined polymeric nanostructures, on the same size scale as proteins and cellular structures, are promising vehicles for diagnostics and drug delivery [4]. The capability to carry and release a therapeutic payload in a controlled way, coupled to imaging ability opens the way to theragnostics [5]. A major limitation in the use of (polymeric) nanoparticles in vivo is their premature elimination from the circulatory system by the mononuclear phagocyte system (MPS), which prevents the nanoparticles from reaching their target [6]. The disposal of particles through the MPS begins with the adsorption of serum proteins (opsonins) onto the surface of the nanoparticles, followed by macrophage recognition, phagocytosis, and subsequent sequestration in the liver, spleen, and/or bone marrow. To address these limitations, several methods have been developed to mask or camouflage nanoparticles from the MPS. Among these, the preferred one is the grafting of poly(ethylene glycol) (PEG) onto the surface of nanoparticles [7]. The purpose of the PEG chains is to block the adhesion of opsonins present in the blood serum, such that the particles remain invisible to phagocytic cells. Using transmission electron microscopy, it has been possible to visualize the protein rejecting capabilities of PEGylated surfaces [8]. PEG 5000 has proved to be a threshold for maximum reduction of protein adsorption [9] and lower uptake in the liver [10].

In recent years, the Michael addition of thiols to acrylates, acrylamides and vinyl sulfones has acquired the status of a click reaction: it can be performed selectively under mild (aqueous) conditions. The major disadvantage of this reaction in comparison to the dipolar addition of azides to terminal alkynes is the possibility of thiol oxidation to disulfide and its inherent 
lack of bio-orthogonality, deriving from many endogenous thiols $[11,12]$. Recently, our research group has reported the preparation of the acrylate ester functionalized dextrin: dexVA. The Michael addition of hexadecanethiol to dexVA generates an amphiphilic material, $\operatorname{dex}_{16}$, which self-assembles in water into well-defined nanoparticles, stable macromolecular micelles (nanogel) [13]. Importantly, the $\mathrm{dex}_{16}$ nanoparticles can be loaded with a hydrophobic cargo, e.g., curcumin (anticancer drug), for drug delivery purposes $[14,15]$.

To evaluate the potential of the $\operatorname{dex}_{16}$ nanogel for drug delivery purposes, the nanogel was labelled, via Michael addition of a thiol functionalized fluorescent probe to the acrylate groups, and its blood clearance was studied in BALB/c mice [16]. Although the blood clearance of the nanogel could be readily followed by fluorescence measurements, its organ distribution profile could not be evaluated, possibly due to quenching effects of the fluorescent probe in the organ's homogenates. It is widely accepted that the physical and chemical properties of the nanoparticles, including particle size, surface charge, and surface hydrophilicity, are important parameters determining their biological fate after intravenous administration [17]. It is, therefore, crucial to devise a labelling methodology that conserves the native nanoparticle properties. To obtain the biodistribution profile of the nanoparticles in experimental animals, we envisaged labelling the nanogel with a radioactive label. With this goal, we have synthesized a new $\omega$-thiol functionalized DOTA-monoamide-type metal chelator (DOTA =1,4,7,10-tetraazacyclododecanetetraacetic acid) for covalent functionalization (via Michael addition) and labelling (complexation) of a suitable $\mathrm{Ln}^{3+}$ (e.g., ${ }^{153} \mathrm{Sm}^{3+}$ ) radioisotope. DOTA-like chelators are well known to form lanthanide(III) chelates of high thermodynamic and kinetic stability, which is of crucial importance for in vivo applications [18].

In the present study, the biodistribution and blood clearance of dextrin nanoparticles labelled with ${ }^{153} \mathrm{Sm}^{3+}$ DOTA-type chelates has been studied in experimental animals after intravenous administration. The effect of surface decoration with PEG on the biodistribution was also evaluated.

\section{Experimental section}

\subsection{Materials}

Dextrin-VA (dexVA) and dextrin-VA-SC 16 (dexC 16 were synthesized as comprehensively described before [13]. DexVA is the dextrin backbone with grafted acrylate ester groups (VA-vinyl acrylate). DexC $\mathrm{C}_{16}$ is composed by the hydrophilic dextrin backbone with grafted VA groups, which are partially substituted with long alkyl chains $\left(\mathrm{SC}_{16}\right)$. In this work, dexC $\mathrm{C}_{16}$ with 13 acrylate groups ( $\left.\mathrm{DS}_{\mathrm{VA}} 13 \%\right)$ and 6 hexadecanethioalkyl chains $\left(\mathrm{DS}_{\mathrm{C} 16} 6 \%\right)$ per 100 dextrin glucopyranoside residues was used.

O-[2-(3-mercaptopropionylamino)ethyl]-O'-methylpolyethylene glycol 5000 (PEG-SH), europium (III) chloride hexahydrate $99.99 \%$, samarium (III) chloride hexahydrate $99 \%$ $\left(\mathrm{SmCl}_{3}\right)$, dimethyl sulfoxide (DMSO), triethylamine (TEA) and deuterium oxide $\left(\mathrm{D}_{2} \mathrm{O}\right)$ were purchased from Aldrich.
Regenerated cellulose tubular membranes, with 3500 MWCO, were obtained from Membrane Filtration Products.

${ }^{153} \mathrm{SmCl}_{3}$ was produced at the Instituto Tecnológico e Nuclear, Lisbon, Portugal with a specific radioactivity of $>5 \mathrm{GBq} \mathrm{mg}^{-1}$. For this purpose, ${ }^{153} \mathrm{Sm}_{2} \mathrm{O}_{3}$ was prepared from a $98 \%{ }^{152} \mathrm{Sm}$ enriched $\mathrm{Sm}_{2} \mathrm{O}_{3}$ target, sealed into a quartz vial and welded into an aluminium can, by neutron irradiation using a thermal flux of $2.3 \times 10^{13} \mathrm{n} \mathrm{cm}^{-2} \mathrm{~s}^{-1}$. After irradiation, the sample was opened, dissolved in $1 \mathrm{M} \mathrm{HCl}$, and the final ${ }^{153} \mathrm{SmCl}_{3}$ solution was brought to a stock concentration of $1.9 \times 10^{-3} \mathrm{M}$.

\subsection{Synthesis of $\omega$-thiol functionalized metal chelator}

Synthesis of tris-tert-butyl 2,2', $2^{\prime \prime}$-(10-(2-((2-(4-mercaptobutanamido)ethyl)amino)-2-oxoethyl)-1,4,7,10-tetraazacyclododecane-1,4,7-triyl)triacetate (3) (scheme 1): to a solution of compound 2 (430 mg, $0.70 \mathrm{mmol})$ in methanol $\left(30 \mathrm{~cm}^{3}\right)$ was added triethylamine $\left(0.17 \mathrm{~cm}^{3}, 1.2 \mathrm{mmol}\right)$ and $\gamma$ butyrothiolactone $(0.61 \mathrm{~g}, 6.0 \mathrm{mmol})$. The reaction mixture was stirred at $50{ }^{\circ} \mathrm{C}$ under a nitrogen atmosphere for $6 \mathrm{~h}$ and left stirring at room temperature overnight. The reaction mixture was concentrated under reduced pressure and the residue was purified by a flash chromatography $\left(100 \% \mathrm{CH}_{2} \mathrm{Cl}_{2} \rightarrow \mathrm{CH}_{2} \mathrm{Cl}_{2} / \mathrm{EtOH}\right.$ (70:30)) to afford the title compound (3) as a colourless oil (0.162 g, 32\%). ${ }^{1} \mathrm{H}$ NMR $\left(300 \mathrm{MHz}, \mathrm{D}_{2} \mathrm{O}\right): \delta=1.46(\mathrm{~s}, 27 \mathrm{H}$, tert$\mathrm{Bu}), 1.97\left(\mathrm{~m}, 2 \mathrm{H}, \mathrm{C}(\mathrm{O}) \mathrm{CH}_{2} \mathrm{CH}_{2} \mathrm{CH}_{2} \mathrm{SH}\right), 2.49(\mathrm{~m}, 2 \mathrm{H}$, $\left.\mathrm{C}(\mathrm{O}) \mathrm{CH}_{2} \mathrm{CH}_{2} \mathrm{CH}_{2} \mathrm{SH}\right), 2.57$ (m, $2 \mathrm{H}, \mathrm{C}(\mathrm{O}) \mathrm{CH}_{2} \mathrm{CH}_{2} \mathrm{CH}_{2} \mathrm{SH}$ ), 2.20-3.80 (broad, overlapped signals with a integration corresponding to approximately $28 \mathrm{H}, \mathrm{N}\left(\mathrm{CH}_{2}\right)_{2} \mathrm{~N}, \mathrm{NCH}_{2} \mathrm{C}(\mathrm{O})$ and $\mathrm{C}(\mathrm{O}) \mathrm{NHCH}_{2} \mathrm{CH}_{2} \mathrm{NHC}(\mathrm{O})$ ), 8.2 and 8.6 (broad signals, $\left.\mathrm{C}(\mathrm{O}) \mathrm{NHCH}_{2} \mathrm{CH}_{2} \mathrm{NHC}(\mathrm{O})\right)$.

Synthesis of 2,2', $2^{\prime \prime}$-(10-(2-((2-(4-mercaptobutanamido)ethyl)amino)-2-oxoethyl)-1,4,7,10-tetraazacyclododecane-1,4, 7-triyl)triacetic acid (4): compound (3) (162 mg, $226 \mu \mathrm{mol})$ was dissolved in a mixture ethanol/aqueous $\mathrm{HCl} 6 \mathrm{M}(1 / 1 \mathrm{v} / \mathrm{v}$; $20 \mathrm{~cm}^{3}$ ) and left to stirring overnight at room temperature. The solution was concentrated under reduced pressure and further dried under vacuum to afford the title compound (4), in the hydrochloride form, as a white vitreous solid $(121 \mathrm{mg}) .{ }^{1} \mathrm{H}$ NMR $\left(300 \mathrm{MHz}, \mathrm{D}_{2} \mathrm{O}\right): \delta=1.88(\mathrm{~m}$, $\left.2 \mathrm{H}, J=7.5 \mathrm{~Hz}, \mathrm{C}(\mathrm{O}) \mathrm{CH}_{2} \mathrm{CH}_{2} \mathrm{CH}_{2} \mathrm{SH}\right), 2.38(\mathrm{t}, 2 \mathrm{H}, J=$ $\left.7.5 \mathrm{~Hz}, \mathrm{C}(\mathrm{O}) \mathrm{CH}_{2} \mathrm{CH}_{2} \mathrm{CH}_{2} \mathrm{SH}\right), 2.54(\mathrm{t}, J=6.9 \mathrm{~Hz}, 2 \mathrm{H}$, $\mathrm{C}(\mathrm{O}) \mathrm{CH}_{2} \mathrm{CH}_{2} \mathrm{CH}_{2} \mathrm{SH}$ ), 3.00-3.70 (broad, overlapped signals with a integration corresponding to approximately $28 \mathrm{H}$, $\mathrm{N}\left(\mathrm{CH}_{2}\right)_{2} \mathrm{~N}, \mathrm{NCH}_{2} \mathrm{C}(\mathrm{O})$ and $\left.\mathrm{C}(\mathrm{O}) \mathrm{NHCH}_{2} \mathrm{CH}_{2} \mathrm{NHC}(\mathrm{O})\right) .{ }^{13} \mathrm{C}$ NMR (75.4 MHz, $\mathrm{D}_{2} \mathrm{O}$ ): $24.82\left(\mathrm{C}(\mathrm{O}) \mathrm{CH}_{2} \mathrm{CH}_{2} \mathrm{CH}_{2} \mathrm{SH}\right)$, $34.34\left(\mathrm{C}(\mathrm{O}) \mathrm{CH}_{2} \mathrm{CH}_{2} \mathrm{CH}_{2} \mathrm{SH}\right), 37.12\left(\mathrm{C}(\mathrm{O}) \mathrm{CH}_{2} \mathrm{CH}_{2} \mathrm{CH}_{2} \mathrm{SH}\right)$, $38.61\left(\mathrm{CH}_{2}\right), 38.83\left(\mathrm{CH}_{2}\right), 39.88\left(\mathrm{CH}_{2}\right), 41.74\left(\mathrm{CH}_{2}\right), 48.21$ $\left(\mathrm{CH}_{2}\right), 48.84\left(\mathrm{CH}_{2}\right), 50.54\left(\mathrm{CH}_{2}\right), 51.30\left(\mathrm{CH}_{2}\right), 51.57\left(\mathrm{CH}_{2}\right)$, $53.49\left(\mathrm{CH}_{2}\right), 55.71\left(\mathrm{CH}_{2}\right), 55.83\left(\mathrm{CH}_{2}\right), 56.50\left(\mathrm{CH}_{2}\right), 170.66$ $(\mathrm{C}(\mathrm{O}) \mathrm{OH}), 173.25(\mathrm{C}(\mathrm{O}) \mathrm{OH}), 174.92(\mathrm{C}(\mathrm{O}) \mathrm{NH}), 176.42$ (C(O)NH). MS (ESI-LR): m/z (\%): 577.5 (18), 571.5 (66.5) $[\mathrm{M}+\mathrm{Na}]^{+}, 549.5(100)[\mathrm{M}+\mathrm{Na}]^{+}, 447.5(5)$. 


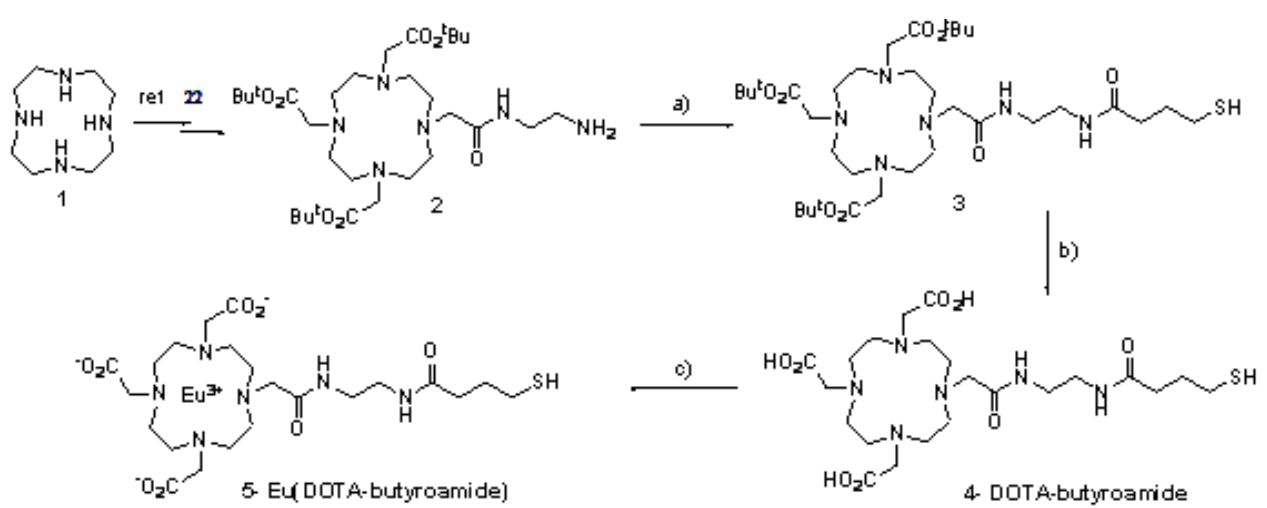

Scheme 1. Synthesis of the $\omega$-thiol functionalized metal chelator DOTA-butyramide (4) and its Eu ${ }^{3+}$ complex (5): (a) $\gamma$-butyrothiolactone/TEA/MeOH; (b) $\mathrm{HCl} / \mathrm{EtOH}$; (c) $\mathrm{EuCl}_{3} \cdot 6 \mathrm{H}_{2} \mathrm{O}$.

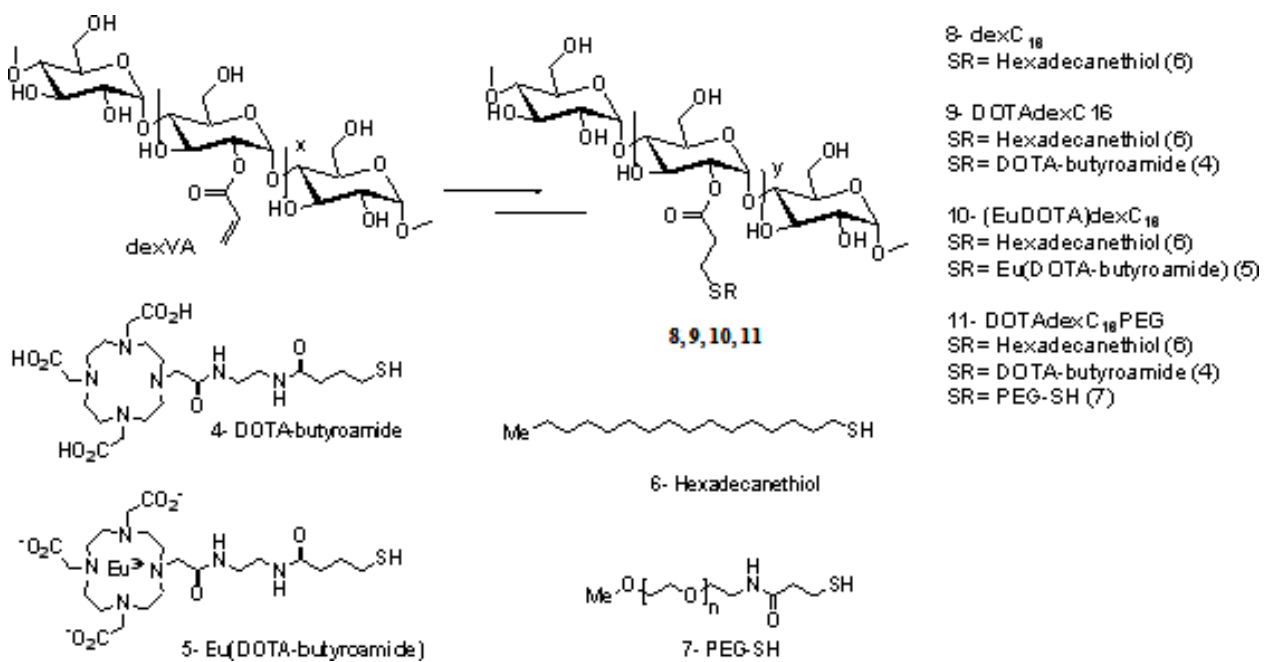

Scheme 2. Synthesis of the DOTAdex $\mathrm{C}_{16}$ and DOTAdex $\mathrm{C}_{16} \mathrm{PEG}$ and its $\mathrm{Eu}^{3+}$ complexes.

\subsection{Preparation of DOTAdex $C_{16}$ or DOTAdex $C_{16} P E G$ materials}

In the first step dexVA was reacted with the $\omega$-thiolfunctionalized metal chelator (4) to afford the metal chelator grafted material. In the second step, hexadecanethiol was added to the former material to afford the DOTAdexC $\mathrm{C}_{16}$ material (9). Finally, a thiol functionalized PEG molecule was added to produce the DOTAdexC ${ }_{16}$ PEG material (11).

DexVA is the dextrin backbone with grafted acrylate ester groups (VA-vinyl acrylate). For the sake of simplicity, in scheme 2, the grafted acrylate groups are represented at position 2 of the glucopyranoside ring (major regioisomer), although grafting in position 3 (minor regioisomer) can be detected by ${ }^{1} \mathrm{H}$ NMR, as reported before [19]. DexC $\mathrm{C}_{16}$ is composed by the hydrophilic dextrin backbone with grafted VA groups, which are partially substituted with hexadecanethiol chains ( $\mathrm{SR}=$ hexadecanethiol). In this work, $\operatorname{dex} \mathrm{C}_{16}(\mathbf{8})$ with 13 acrylate groups $\left(\mathrm{DS}_{\mathrm{VA}} 13 \%\right)$ and 6-hexadecanethiol chains $\left(\mathrm{DS}_{\mathrm{C} 16} 6 \%\right)$ per 100 dextrin glucopyranoside residues was used. For the sake of clarity the unreacted VA ester groups are not shown on the materials (only substituted VA ester groups are represented). DexVA (50 mg, $\mathrm{DS}_{\mathrm{VA}} 13 \%, 38.45 \mu \mathrm{mol}$ equivalent VA) was dissolved in DMSO $\left(0.931 \mathrm{~cm}^{3}\right)$. To this solution was added a solution of compound 4 (11 mg, $19.23 \mu \mathrm{mol}, 50 \% \mathrm{~mol}$ to VA groups) and triethylamine (16 $\mu \mathrm{l}$, $0.115 \mathrm{mmol}, 3$ molar equivalents to VA groups). The medium was stirred for $24 \mathrm{~h}$, at $50^{\circ} \mathrm{C}$. In the second step the addition of 1-hexadecanethiol was performed as previously reported [13]. Briefly, hexadecanethiol (6) $(7.95 \mathrm{mg}, 30.76 \mu \mathrm{mol}, 80 \%$ relatively to VA groups) and triethylamine (11 $\mu 1,38.45 \mu \mathrm{mol}$, 1 mol equivalent to VA groups) were added to the reaction mixture. The medium was stirred for $24 \mathrm{~h}$, at $50^{\circ} \mathrm{C}$. The mixture was dialyzed for $48 \mathrm{~h}$ against water, with frequent water changes. After freeze drying, material (9) was obtained as a white candyfloss-like material and stored at room temperature.

DOTAdexC $\mathrm{C}_{16} \mathrm{PEG}$ (11) was obtained by dissolving DOTAdexC $_{16}$ (9) (15 mg, $12.2 \mu \mathrm{mol}$ equivalent VA), PEG-SH (18 mg, $3.66 \mu \mathrm{mol}, 30 \% \mathrm{~mol}$ to VA groups) and triethylamine (3.4 $\mu \mathrm{l}, 24.4 \mu \mathrm{mol}, 2 \mathrm{~mol}$ equivalent to VA groups) in DMSO $\left(0.295 \mathrm{~cm}^{3}\right)$. The mixture was stirred for $24 \mathrm{~h}$, at $50^{\circ} \mathrm{C}$ and then dialyzed for $48 \mathrm{~h}$ against water, with frequent water changes. After freeze drying, the product was obtained as a white candyfloss-like material and stored at room temperature. 


\subsection{Complexation of $\mathrm{Eu}^{3+}$ with $\omega$-thiol functionalized chelator and DOTAdex $C_{16}$ materials}

In order to ascertain the success of DOTA coupling to dex $\mathrm{C}_{16}$ and its chelating capacity, DOTAdex $\mathrm{C}_{16}$ or the soluble metal chelator (4) were complexed with $\mathrm{Eu}^{3+}$ as a model metal ion. The [Eu(DOTAdex $\left.\left.\mathrm{C}_{16}\right)\right]$ complex was prepared by mixing a solution of $\mathrm{EuCl}_{3} \cdot 6 \mathrm{H}_{2} \mathrm{O}$ with a solution of DOTAdexC $\mathrm{C}_{16}$ in $\mathrm{D}_{2} \mathrm{O}$. A slight excess $(5 \%)$ of $\mathrm{Eu}^{3+}$ was used in relation to the amount of metal chelator (4) used in the synthesis of the DOTAdex $\mathrm{C}_{16}$ material. The reaction mixture was adjusted to pH 5.5 by adding aqueous $\mathrm{NaOD}(0.1 \mathrm{mM})$ and was allowed to react for $24 \mathrm{~h}$ at $50{ }^{\circ} \mathrm{C}$. The reaction mixture was adjusted to $\mathrm{pH} 7.0$, filtered through a $0.2 \mu \mathrm{m}$ filter and characterized by ${ }^{1} \mathrm{H}$ NMR, DLS and zeta potential measurements.

The number of DOTA groups attached to the polymer backbone was estimated by back titration of excess (uncomplexed) $\mathrm{Eu}^{3+}$ metal with EDTA in the presence of the complexometric indicator, xylenol orange [20]. The amount of chelator agent grafted to the dexC $\mathrm{C}_{16}$ material was estimated $0.152 \mu \mathrm{mol}$ of DOTA chelator units/mg DOTAdex $\mathrm{C}_{16}$ material.

\subsection{Preparation of $\left[{ }^{153} \operatorname{Sm}\left(\right.\right.$ DOTAdex $\left.\left.C_{16}\right)\right]$ and $\left[{ }^{153} \mathrm{Sm}\left(\mathrm{DOTAdex} \mathrm{C}_{16} \mathrm{PEG}\right)\right]$ chelates for biodistribution studies}

To a dispersion of DOTAdexC $\mathrm{C}_{16}$ or DOTAdexC $\mathrm{C}_{16}$ PEG (5 mg) in sodium acetate buffer (400 $\mu \mathrm{l}, 0.4 \mathrm{M}, \mathrm{pH} 5){ }^{153} \mathrm{SmCl}_{3}$ $(1 \mathrm{mCi})$ was added. Each solution was stirred at $80^{\circ} \mathrm{C}$ for $5 \mathrm{~h}$. After that, cold $\mathrm{SmCl}_{3}$ was added to each solution in order to obtain an equimolar $\mathrm{Sm}^{3+}$ :DOTA ratio. The final solution was heated at $80^{\circ} \mathrm{C}$ for $2 \mathrm{~h}$ and stayed overnight at room temperature. The radiolabelled nanoparticles were purified using a Sephadex G-25 column eluted with $0.4 \mathrm{M}$ acetate buffer. The nanoparticle dispersions were concentrated by centrifugal filtration (centricons, MWCO $10 \mathrm{kDa}$ ) to afford the pure radioligands. The complexation yield is ca $50 \%$ in both cases.

\subsection{Size distribution and zeta potential}

The size distribution and zeta potential of nanoparticles were determined with a Malvern Zetasizer, NANO ZS (Malvern Instruments Limited, UK), using a $\mathrm{He}-\mathrm{Ne}$ laser (wavelength of $633 \mathrm{~nm}$ ) and a detector angle of $173^{\circ}$. Nanoparticle dispersion $(1 \mathrm{ml})$ was analyzed at $25^{\circ} \mathrm{C}$ and $1.0 \mathrm{mg} \mathrm{ml}^{-1}$. The DLS analysis provides the characterization of a sample through the mean value ( $z$-average) for the size and a width parameter known as the polydispersity or polydispersity Index (PdI). The $z$-average diameter is the mean hydrodynamic diameter, determined from the intensity of scattered light, which can be converted to other distributions. In the present work, the $z$-average is considered the best approach to the actual nanoparticles' size. Nanoparticle dispersion was analyzed in a polystyrene cell or in a folded capillary cell, for size distribution or zeta potential measurements, respectively. The zeta potential values were calculated using the Smoluchowski equation [21]. Repeated measurements were performed for each analysis (three times) and the values reported are average values.

\section{7. ${ }^{1} H N M R$}

Nanoparticles were dispersed in deuterium oxide $\left(10 \mathrm{mg} \mathrm{ml}^{-1}\right)$. Dispersions were transferred to $5 \mathrm{~mm}$ NMR tubes. 1D ${ }^{1} \mathrm{H}$ NMR measurements were performed with a VARIAN UNITY Plus 300 spectrometer operating at 299.94 MHz. 1D ${ }^{1} \mathrm{H}$ NMR spectra were measured at $298 \mathrm{~K}$ with 80 scans, a spectral width of $4800 \mathrm{~Hz}$, a relaxation delay of $1 \mathrm{~s}$ between scans and an acquisition time of $3.75 \mathrm{~s}$.

\subsection{Blood clearance and biodistribution studies}

The biodistribution of dextrin nanoparticles labelled with ${ }^{153} \mathrm{Sm}^{3+}$ was evaluated following intravenous administration in Wistar rats. Groups of four animals were anaesthetized and injected in the femoral vein with ca $100 \mu \mathrm{l}(20-100 \mu \mathrm{Ci})$ of the nanoparticles mixture. After pre-defined periods of time, the rats were sacrificed and their tissues (liver, spleen, lungs, bone (femur of left hind leg), intestines (small and large), kidney, heart and brain) were excised, weighed and tissue radioactivity measured in a $\gamma$ well counter. Blood samples were obtained at appropriate periods of time, weighted and radioactivity counted. The same procedure was used to evaluate the influence of the presence of PEG chains in the nanoparticles biodistribution: a group of four animals was injected in the femoral vein with the radiolabelled DOTAdexC ${ }_{16}$ PEG and sacrificed $2 \mathrm{~h}$ later for organ collection. The national regulations for the care and use of laboratory animals have been observed in this study.

\section{Results and discussion}

\subsection{Synthesis of $\omega$-thiol functionalized metal chelator}

We have previously described the synthesis of the bifunctional metal prochelator (2) bearing a functional amine group ready for conjugation to (bio)molecules [22]. In this work, we have used $\gamma$-butyrothiolactone as a protected activated $\omega$-thiol carboxylic acid equivalent (scheme 1). This procedure allows performing the amide coupling without coupling reagents, avoiding potential purification problems related to the removal of the urea byproducts and auxiliary nucleophiles. Acidic deprotection of the $\omega$-thiol functionalized prochelator (3) afforded the chelator (4), in the hydrochloride form, in an aggregate $31 \%$ yield over two steps. DOTA-monoamidetype metal chelators and its conjugates form $\mathrm{Ln}^{3+}$ complexes of high thermodynamic and kinetic stability, as required for in vivo studies, given the toxic effects of free (unchelated) $\mathrm{Ln}^{3+}$ ions.

\subsection{Preparation of DOTAdex $\mathrm{C}_{16}$ or $\mathrm{DOTAdex} \mathrm{C}_{16} \mathrm{PEG}$ materials}

With the $\omega$-thiol functionalized DOTA synthon (4) on hand, one can envisage two pathways for the synthesis of the DOTAdex $\mathrm{C}_{16}$ material: either, performing first the Michael addition of the $\omega$-thiol functionalized metal chelator to the acrylate functionalized dextrin (dexVA), followed by the Michael addition of hexadecanethiol, or by reversing the 


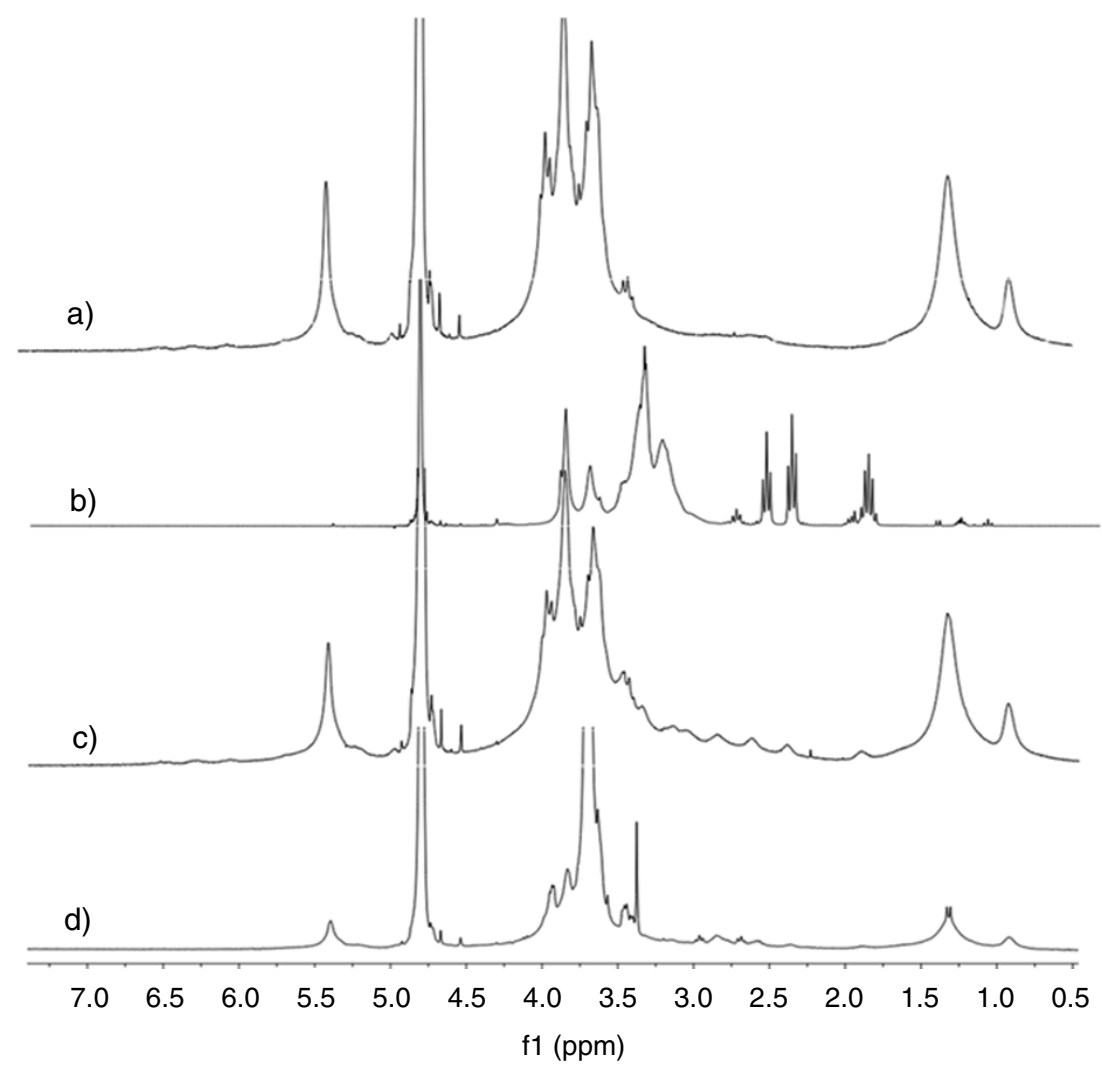

Figure 1. ${ }^{1} \mathrm{H}$ NMR spectra of (a) dexC $\mathrm{C}_{16}$, (b) DOTA-butyramide, (c) DOTAdexC $\mathrm{C}_{16}$ and (d) DOTAdexC ${ }_{16}$ PEG.

addition order. We have noted before, during the synthesis of the dexC $\mathrm{C}_{16}$ material, that even using a large molar excess of hexadecanethiol in relation to the acrylate groups does not give a full acrylate addition. Some acrylate groups are much less reactive, possibly reflecting their grafting position on the glucopyranoside ring and/or some degree of steric hindrance. By first grafting the metal chelator to the acrylate functionalized dextrin allows using a large excess of hexadecanethiol (cheap, commercially available reagent) in the second step in order to push the degree of substitution towards the optimal value. We have established previously that the $\operatorname{dex}_{16}$ material with $\mathrm{DS}_{\mathrm{VA}} 13 \%$ and $\mathrm{DS}_{\mathrm{C} 16} 6 \%$ is suitable for forming stable nanoparticles within a narrow size range. In the ${ }^{1} \mathrm{H}$ NMR spectrum of the dexC $\mathrm{C}_{16}$ material (figure 1(a)) signals assigned to the hexadecane moiety ( $\delta=0.75-1.75 \mathrm{ppm})$ are clearly visible. The ${ }^{1} \mathrm{H}$ NMR spectrum of the DOTAdexC $\mathrm{C}_{16}$ material (figure 1(c)) displays a set of new broad low intensity signals assigned to the grafted DOTA-butyramide chelator (e.g., $\delta=1.9,2.4$ and $2.7 \mathrm{ppm}$, assigned to the methylene groups of the terminal mercaptobutyl moiety) as can be inferred from the ${ }^{1} \mathrm{H}$ NMR spectrum of the DOTA chelator (figure 1(b)). Importantly, signals assigned to unreacted acrylate groups on the dextrin backbone $(\delta=6.0-6.6 \mathrm{ppm})$ can also be seen in figures 1 (a) and (c). The unreacted acrylate groups allow further functionalization of the nanogel with thiol functionalized PEG molecule. PEG grafting was confirmed by disappearance of the signals (figure 1(d)) assigned to unreacted acrylate ester groups and the appearance of a new intense signal $(\delta=3.6 \mathrm{ppm})$ assigned to the methylene groups of the grafted PEG molecule. The ${ }^{1} \mathrm{H}$ NMR spectrum of the DOTAdex $\mathrm{C}_{16}$ PEG material (figure $1(\mathrm{~d})$ ) displays new signals assigned to the PEG moiety ( $\delta=3.4$ and $3.6 \mathrm{ppm}$ ) confirming the PEGylation of the nanoparticles.

\subsection{Characterization of the nanoparticles}

The DOTA coupling to the dextrin nanoparticles was used as a tool to obtain a $\mathrm{Ln}^{3+}$ chelate which could be used as (radioactive) label for biodistribution studies. The high detection sensitivity of $\gamma$-emitting radioisotopes, e.g., ${ }^{153} \mathrm{Sm}^{3+}$, ensures that a low degree of substitution on metal chelate allows sensitive detection, as required for biodistribution studies. Moreover, the formation of neutral $\mathrm{Ln}^{3+}$-DOTA-monoamide complexes ensures that the labelling procedure does not substantially change the structure and/or the overall (neutral) charge of the original (unlabelled) nanoparticles, and therefore is not expected to interfere in the biodistribution studies.

The size distribution and the zeta potential of the nanoparticles from different materials were determined by dynamic light scattering measurements (table 1).

As can be seen from table 1, the functionalization of the nanoparticles with the DOTA metal chelator does not have a substantial effect on the mean diameter of the nanoparticles. For $\operatorname{dexC}_{16}$ the nanoparticles size increased from 23.9 to $25.3 \mathrm{~nm}$, after coupling of the metal chelator. For $\operatorname{dexC}_{16} \mathrm{PEG}$ a similar increase was observed, from 32.4 to $37.1 \mathrm{~nm}$. In contrast, the PEG functionalization increases substantially the 


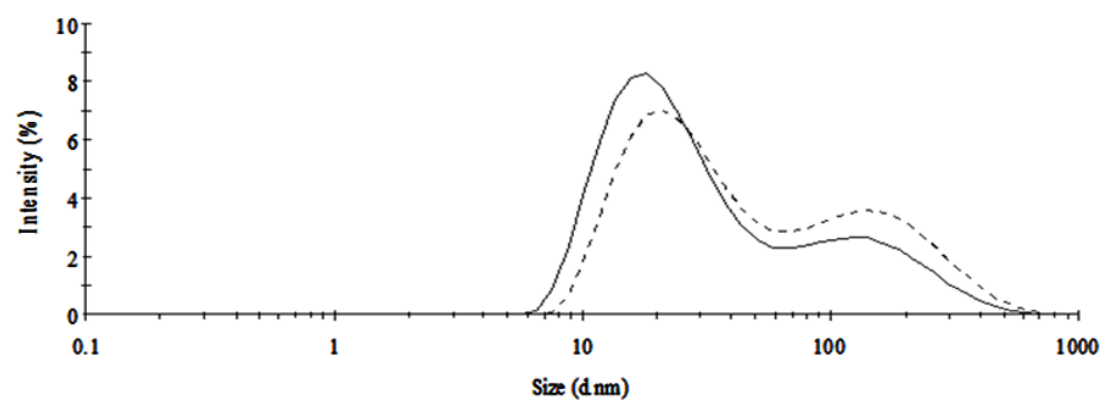

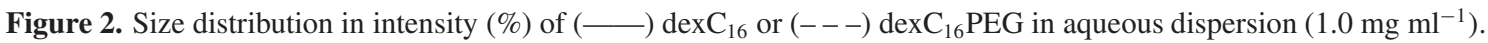

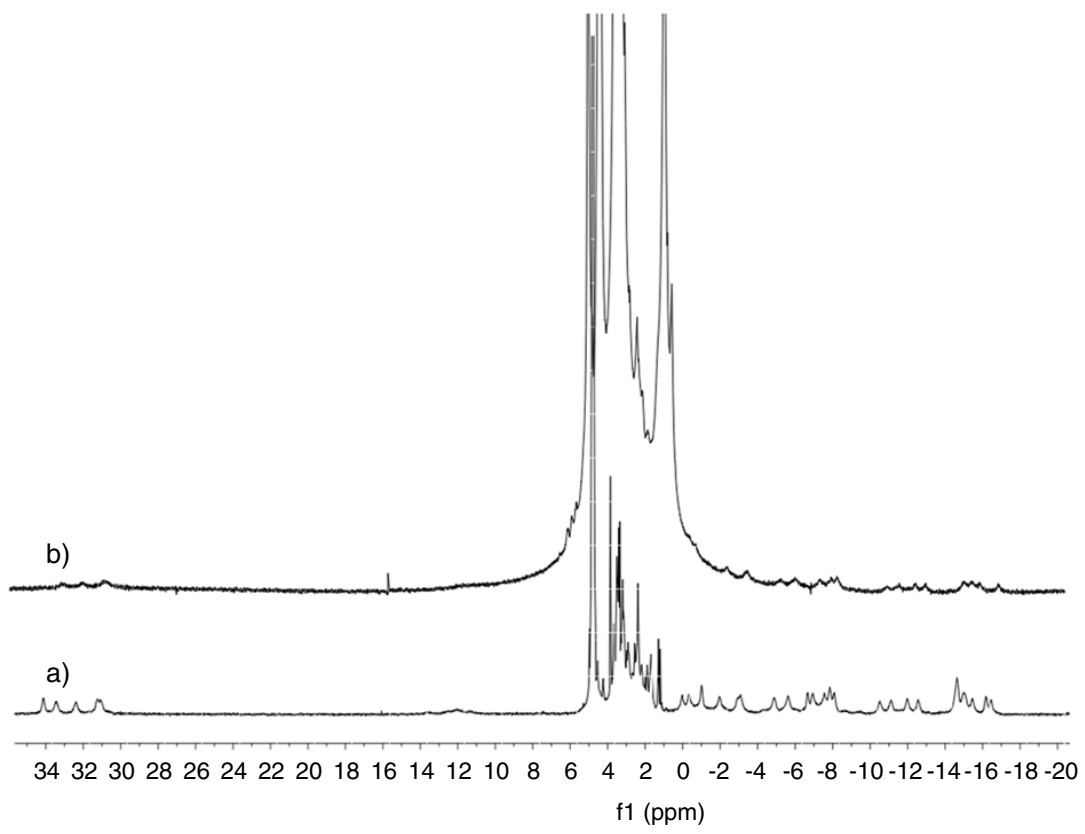

Figure 3. ${ }^{1} \mathrm{H}$ NMR spectra of (a) $\mathrm{Eu}(\mathrm{DOTA})$ and (b) $\left[\mathrm{Eu}\left(\mathrm{DOTAdexC}_{16}\right)\right]$.

Table 1. DLS analysis of the nanoparticles from different materials in aqueous dispersion $\left(1.0 \mathrm{mg} \mathrm{ml}^{-1}\right), \mathrm{pH} 7.0$.

\begin{tabular}{llll}
\hline Material & $z$-avg $(\mathrm{nm})$ & PdI & Zeta potential $(\mathrm{mV})$ \\
\hline dexC $_{16}$ & 23.9 & 0.388 & -4.02 \\
dexC $_{16}$ PEG & 32.4 & 0.442 & -8.59 \\
DOTAdexC $_{16}$ & 25.3 & 0.341 & -17.8 \\
[Eu(DOTAdexC $\left.\left._{16}\right)\right]$ & - & - & -1.35 \\
DOTAdexC $_{16}$ PEG & 37.1 & 0.275 & - \\
\hline
\end{tabular}

hydrodynamic diameter of the nanoparticles. Figure 2 shows the size distribution obtained by DLS for the nanoparticles from the dexC $\mathrm{C}_{16}$ and dex $\mathrm{C}_{16}$ PEG materials. PEG decoration does not change the nanoparticle population distribution, only a shift to larger sizes is observed, suggesting that PEGylation does not change the nanoparticles structure. This is consistent with the formation of an exterior hydrophilic PEG corona projecting into the aqueous media. The observed increase in nanoparticle's size is similar to that observed for other types of nanoparticles (e.g. gold nanoparticles) following grafting with PEG 5000 [23].

The surface functionalization of the $\operatorname{dex}_{16}$ nanoparticles with PEG is expected to affect its interaction with proteins and cells, and thus its fate in vivo. The PEG hydrophilic corona may avoid the recognition and uptake of the nanoparticles by the organs of the MPS increasing the blood circulation half-life, as reported by other authors working on different nanoparticulate materials [24].

Zeta potential measurements were carried out to evaluate the nanoparticles' surface charge. The change of the zeta potential of the $\operatorname{dex}_{16}$ nanoparticles, from a near neutral value $(-4.02 \mathrm{mV})$ to a negative value $(-17.8 \mathrm{mV})$ at $\mathrm{pH} 7.0$, following functionalization with the metal chelator, confirms the grafting of the metal chelator. The grafted DOTAmonoamide macrocycle is expected to bear an overall negative charge at $\mathrm{pH}$ 7.0. Moreover, after complexation of the DOTAdex $\mathrm{C}_{16}$ nanoparticles with $\mathrm{Eu}^{3+}$, the zeta potential value returns to a near neutral value, similar to that of the original $\operatorname{dexC}_{16}$ nanoparticles [25], consistent with the formation of neutral [Eu(DOTAdexC $\left.\left.\mathrm{D}_{16}\right)\right]$ complexes.

The ${ }^{1} \mathrm{H}$ NMR spectrum of the [Eu(DOTAdexC $\left.C_{16}\right)$ ] material (figure 3(b)) confirms that the $\mathrm{Eu}^{3+}$ complexation effectively occurred. In the NMR spectra of the Eu(DOTAbutyramide) chelate (5) (figure 3(a)) and [Eu(DOTAdexC $\left.\mathrm{C}_{16}\right)$ ] material (figure 3(b)) the $\mathrm{CH}_{2}$ resonances within the macrocycle and pendant acetate display strong paramagnetic 


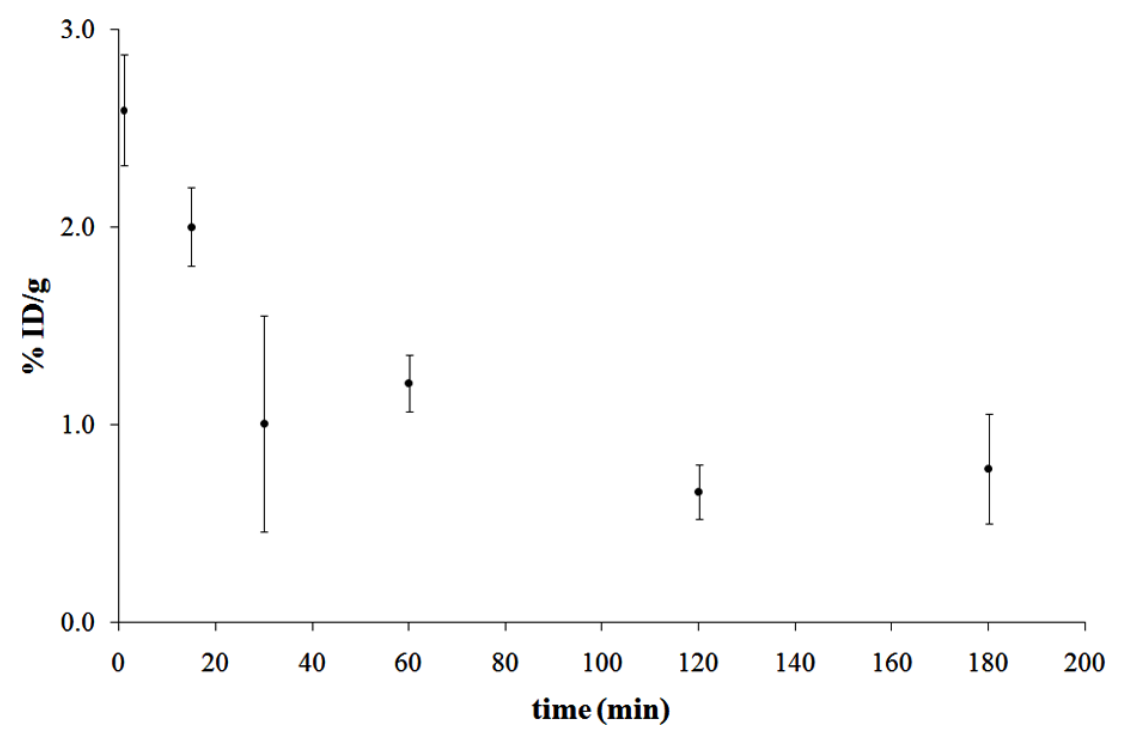

Figure 4. Blood clearance profile of radiolabelled nanoparticles. The error bars correspond to the standard deviation $(N=4)$.

shifts as reported before for glycoconjugates of Eu(DOTAmonoamide) chelates [22]. The amount of metal chelator grafted to the $\operatorname{dexC}_{16}$ material was estimated by back titration of excess $\mathrm{Eu}^{3+}$ with EDTA in the presence of the complexometric indicator xylenol orange: circa $0.152 \mu \mathrm{mol}$ of DOTA-butyramide per $\mathrm{mg}$ of DOTAdexC $\mathrm{C}_{16}$ material. The $\mathrm{Eu}^{3+}$ complexation was used as a model system for the labelling of the nanoparticles with the radioisotope ${ }^{153} \mathrm{Sm}^{3+}$ for biodistribution studies. These studies confirm that nanoparticles' features (size and surface potential) are conserved after labelling. Consequently, the biodistribution of the labelled nanoparticles is expected to be representative of the original (unlabelled) nanoparticles.

\subsection{Blood clearance and biodistribution studies}

We have attempted previously to perform biodistribution studies of the $\operatorname{dexC}_{16}$ nanoparticles, using FITC-labelled dextrin nanoparticles [16]. Although succeeding in evaluating the nanoparticles blood clearance, we failed in our attempts to characterize the organ accumulation. In the present work, labelling the nanoparticles with ${ }^{153} \mathrm{Sm}^{3+}$ effectively allowed us to study the nanoparticles blood clearance and to obtain the biodistribution profile in vivo.

The blood clearance profile of ${ }^{153} \mathrm{Sm}^{3+}$-labelled nanoparticles in Wistar rats, after intravenous injection, is shown in figure 4 . The clearance of the nanoparticles from the systemic circulation is relatively fast in the first hour, proceeding afterwards at a lower rate. In the first $15 \mathrm{~min}$, about $23 \%$ of the nanoparticles were removed from the bloodstream. At $1 \mathrm{~h}$ after injection, $47 \%$ of the injected dose is still detected in the bloodstream, followed by a further reduction $2 \mathrm{~h}$ later to about $30 \%$. The blood clearance profile obtained is very similar to the one previously reported, using FITC-labelled dextrin nanoparticles [16].

The organ biodistribution of the $\left[{ }^{153} \mathrm{Sm}\left(\right.\right.$ DOTAdex $\left.\left.\mathrm{C}_{16}\right)\right]$ in Wistar rats was evaluated at different time points. Figure 5

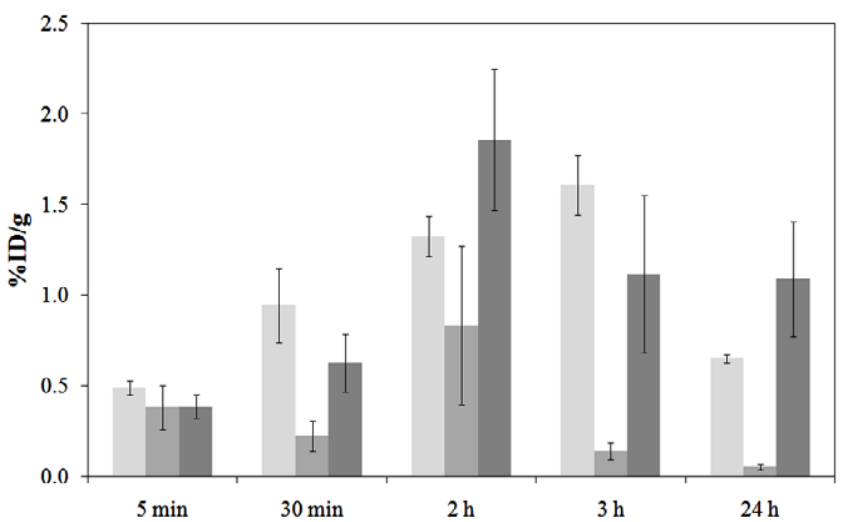

Figure 5. Biodistribution in ( $\square$ ) liver, ( $\square$ ) kidney and ( $\square$ ) spleen of Wistar rats $5 \mathrm{~min}, 30 \mathrm{~min}, 2 \mathrm{~h}, 3 \mathrm{~h}, 24 \mathrm{~h}$ after i.v. injection of $\left[{ }^{153} \mathrm{Sm}\right.$ (DOTAdex $\mathrm{C}_{16}$ )] stated as the percentage of injected dose per gram of organ $(\% \mathrm{ID} / \mathrm{g})$. Results are the mean of four animals.

and table 2 (supplemental information-SI available at stacks.iop.org/Nano/21/295103/mmedia) show representative data stated as the percentage of the injected dose per gram of tissue $(\% \mathrm{ID} / \mathrm{g})$.

The radioactivity was located mainly in the liver, spleen and kidneys (figure 5), with low $\% \mathrm{ID} / \mathrm{g}$ found in the other organs (table 2, see SI available at stacks.iop.org/ Nano/21/295103/mmedia), in the time frame analyzed in the experiment. These results suggest that the removal of nanoparticles occurs by phagocytosis, since liver and spleen are macrophage-rich organs, consistently with the previous observation of in vitro internalization of nanoparticles by macrophages [16]. The maximum activity detected in the liver and spleen gradually increases from the first data obtained ( $5 \mathrm{~min}$ ), reaching its maximum $2 \mathrm{~h}$ after injection, parallelling the decreasing profile of the blood activity (see above). The reduction of activity observed after $2 \mathrm{~h}$ suggests that the material does not accumulate in the organs, presumably being metabolized and excreted. As can be seen in figure 5 there 


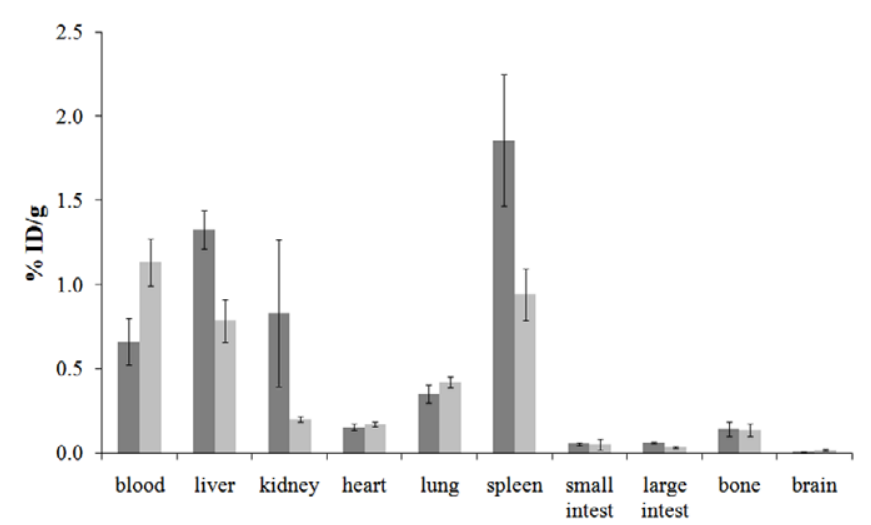

Figure 6. Comparison of the biodistribution in Wistar rats $2 \mathrm{~h}$ after i.v. injection of $(\square)\left[{ }^{153} \mathrm{Sm}\left(\right.\right.$ DOTAdexC $\left.\left.C_{16}\right)\right]$ or $(\square)$

$\left[{ }^{153} \mathrm{Sm}\right.$ (DOTAdex $\left.\left.\mathrm{C}_{16} \mathrm{PEG}\right)\right]$. Results are the mean of four animals.

is some renal uptake of nanoparticles, and excretion in the urine was detected (data not shown), thus reinforcing the hypothesis of kidney filtration of the smallest nanoparticles. Zhang et al, reported that $20 \mathrm{~nm}$ pegylated gold nanoparticles are also excreted through renal filtration [23]. They assumed that the samples of gold nanoparticles contained a small fraction of nanoparticles with diameters $<5 \mathrm{~nm}$, which could be excreted via the urinary system. In the current case, small dextrin nanoparticles are also likely to be present in the fairly polydisperse materials. Furthermore, it may be hypothesized that the self-assembled material is flexible enough to cross the renal filtration system, which would be expected to exclude rigid nanoparticles of the same size range. It must be remarked that only few studies are available reporting the biodistribution of self-assembled polymeric nanoparticles; furthermore, the existing studies do not include nanoparticles in the size range used in this study.

To avoid a rapid blood clearance, the nanoparticles should retard opsonization and macrophage recognition, which results in sequestration by the MPS organs. The decoration with PEG was tested in this work with the purpose of improving the circulation time. Figure 6 compares the 2 h organ distribution of labelled nanoparticles, coated or not with PEG.

The results obtained confirm the well documented stealth effect: PEG reduces opsonization, presumably by steric and hydration effects, improving blood circulation time and reducing the accumulation in the liver and spleen [24].

The decoration with PEG increases significantly the hydrodynamic diameter of the nanoparticles. Although larger particles have been reported as being taken up faster by the MPS [26], the increased size is, in the current case, effectively counterbalanced by the PEG steric and hydration effects, overall resulting in reduction of the uptake rate. In general, pegylated nanoparticles were found to have a longer circulation time than the non-pegylated ones.

\section{Conclusion}

Functionalization of dextrin nanoparticles with a metal chelator allows the radioactive labelling of the nanoparticles. The labelling process has no significant effect on the nanoparticles size and surface charge; hence the biodistribution profile obtained in Wistar rats following intravenous administration is considered representative of the unmodified nanoparticles. This strategy is appropriate for in vivo studies, combining a highly sensitive detection technique with minor nanoparticle modifications. The dex $\mathrm{C}_{16}$ nanoparticles display a characteristic biodistribution profile, being mainly taken up by the organs of the MPS-liver and spleen. The blood circulation time extends to several hours, although the concentration is halved in about $1 \mathrm{~h}$. The functionalization of the nanoparticles with PEG 5000 in this formulation improves their circulation time in the bloodstream and reduces the accumulation in the liver and spleen.

\section{Acknowledgments}

The authors wish to acknowledge funding through the FCT/POCTI programme (project PTDC/QUI/70063/2006).

\section{References}

[1] Fernandez-Montesinos R, Castillo P M, Klippstein R, Gonzalez-Rey E, Mejias J A, Zaderenko A P and Pozo D 2009 Chemical synthesis and characterization of silver-protected vasoactive intestinal peptide nanoparticles Nanomedicine 4 919-30

[2] Leary S P, Liu C Y and Apuzzo M L 2006 Toward the emergence of nanoneurosurgery: part II-nanomedicine: diagnostics and imaging at the nanoscale level Neurosurgery 58 805-23

[3] Farokhzad O C and Langer R 2006 Nanomedicine: developing smarter therapeutic and diagnostic modalities Adv. Drug Deliv. Rev. 58 1456-9

[4] Weinstein J S, Varallyay C G, Dosa E, Gahramanov S, Hamilton B, Rooney W D, Muldoon L L and Neuwelt E A 2010 Superparamagnetic iron oxide nanoparticles: diagnostic magnetic resonance imaging and potential therapeutic applications in neurooncology and central nervous system inflammatory pathologies, a review J. Cereb. Blood Flow Metab. 30 15-35

[5] Shubayev V I, Pisanic T R and Jin S H 2009 Magnetic nanoparticles for theragnostics $A d v$. Drug Deliv. Rev. 61 467-77

[6] Owens D E III and Peppas N A 2006 Opsonization, biodistribution, and pharmacokinetics of polymeric nanoparticles Int. J. Pharm. 307 93-102

[7] Peracchia M T, Fattal E, Desmaele D, Besnard M, Noel J P, Gomis J M, Appel M, d'Angelo J and Couvreur P 1999 Stealth PEGylated polycyanoacrylate nanoparticles for intravenous administration and splenic targeting J. Control. Release 60 121-8

[8] Peracchia M T, Harnisch S, Pinto-Alphandary H, Gulik A, Dedieu J C, Desmaele D, d'Angelo J, Muller R H and Couvreur P 1999 Visualization of in vitro protein-rejecting properties of PEGylated stealth polycyanoacrylate nanoparticles Biomaterials 20 1269-75

[9] Gref R, Luck M, Quellec P, Marchand M, Dellacherie E, Harnisch S, Blunk T and Muller R H 2000 'Stealth' corona-core nanoparticles surface modified by polyethylene glycol (PEG): influences of the corona (PEG chain length and surface density) and of the core composition on phagocytic uptake and plasma protein adsorption Colloids Surf. B 18 301-13

[10] Pressly E D et al 2007 Structural effects on the biodistribution and positron emission tomography (PET) imaging of well-defined (64)Cu-labeled nanoparticles comprised of amphiphilic block graft copolymers Biomacromolecules $83126-34$ 
[11] van Dijk M, Rijkers D T, Liskamp R M, van Nostrum C F and Hennink W E 2009 Synthesis and applications of biomedical and pharmaceutical polymers via click chemistry methodologies Bioconjug. Chem. 20 2001-16

[12] Hiemstra C, van der Aa L J, Zhong Z Y, Dijkstra P J and Feijen J 2007 Novel in situ forming, degradable dextran hydrogels by Michael addition chemistry: synthesis, rheology, and degradation Macromolecules 40 1165-73

[13] Gonçalves C, Martins J A and Gama F M 2007 Self-assembled nanoparticles of dextrin substituted with hexadecanethiol Biomacromolecules 8 392-8

[14] Shaikh J, Ankola D D, Beniwal V, Singh D and Kumar M N 2009 Nanoparticle encapsulation improves oral bioavailability of curcumin by at least 9-fold when compared to curcumin administered with piperine as absorption enhancer Eur. J. Pharm. Sci. 37 223-30

[15] Bisht S, Feldmann G, Soni S, Ravi R, Karikar C and Maitra A 2007 Polymeric nanoparticle-encapsulated curcumin ('nanocurcumin'): a novel strategy for human cancer therapy J. Nanobiotechnol. 53

[16] Gonçalves C, Torrado E, Martins T, Pereira P, Pedrosa J and Gama M 2010 Dextrin nanoparticles: studies on the interaction with murine macrophages and blood clearance Colloids Surf. B 75 483-9

[17] Li S D and Huang L 2008 Pharmacokinetics and biodistribution of nanoparticles Mol. Pharm. 5 496-504

[18] Port M, Idee J M, Medina C, Robic C, Sabatou M and Corot C 2008 Efficiency, thermodynamic and kinetic stability of marketed gadolinium chelates and their possible clinical consequences: a critical review Biometals 21 469-90
[19] Carvalho J, Gonçalves C, Gil A M and Gama F M 2007 Production and characterization of a new dextrin based hydrogel Eur. Polym. J. 43 3050-9

[20] Brunisholz G and Randin M 1959 Sur la séparation des terres rares à l'aide de l'acide éthylènediamine-tétraacétique. IX. Procédé en cycle pour le fractionnement des terres yttriques Helv. Chim. Acta 42 1927-38

[21] Hunter R J 1981 Zeta Potential in Colloid Science (New York: Academic)

[22] Andre J P, Geraldes C F G C, Martins J A, Merbach A E, Prata M I M, Santos A C, de Lima J J P and Toth E 2004 Lanthanide (III) complexes of DOTA-glycoconjugates: a potential new class of lectin-mediated medical imaging agents Chem.-Eur. J. 10 5804-16

[23] Zhang G, Yang Z, Lu W, Zhang R, Huang Q, Tian M, Li L, Liang D and Li C 2009 Influence of anchoring ligands and particle size on the colloidal stability and in vivo biodistribution of polyethylene glycol-coated gold nanoparticles in tumor-xenografted mice Biomaterials 30 1928-36

[24] Shan X, Liu C, Yuan Y, Xu F, Tao X, Sheng Y and Zhou $\mathrm{H} 2009$ In vitro macrophage uptake and in vivo biodistribution of long-circulation nanoparticles with poly(ethylene-glycol)-modified PLA (BAB type) triblock copolymer Colloids Surf. B 72 303-11

[25] Gonçalves C and Gama F M 2008 Characterization of the self-assembly process of hydrophobically modified dextrin Eur. Polym. J. 44 3529-34

[26] Gaumet M, Vargas A, Gurny R and Delie F 2008 Nanoparticles for drug delivery: the need for precision in reporting particle size parameters Eur. J. Pharm. Biopharm. 69 1-9 